\title{
Research Article \\ Effects of AC Coils Parameters on Transduction Efficiency of EMAT for Steel Plate Inspection
}

\author{
Xiaochun Song and Yawu Wang \\ School of Mechanical Engineering, Hubei University of Technology, Wuhan 430068, China \\ Correspondence should be addressed to Xiaochun Song; songxc@mail.tsinghua.edu.cn
}

Received 23 July 2014; Accepted 8 September 2014; Published 28 September 2014

Academic Editor: Zhiqiang $\mathrm{Hu}$

Copyright ( 2014 X. Song and Y. Wang. This is an open access article distributed under the Creative Commons Attribution License, which permits unrestricted use, distribution, and reproduction in any medium, provided the original work is properly cited.

\begin{abstract}
In order to improve the transduction efficiency of electromagnetic acoustic transducer (EMAT) for steel plates inspection, the constitutive equation of magnetostrictive material was theoretically derived and simplified while the magnetostrictive force is parallel to the material surface. Based on the multiphysics field FEM, the effects of such excitation parameters as current, frequency, and pulse number in AC coils on magnetostrictive strain were mainly simulated, and the influence of the coil with different winding shapes on magnetostrictive strain was also analyzed. The simulation and experimental results indicate that magnetostrictive strain increases with a continuously increasing excitation current density, but it decreases with the increase of the frequency and pulse number of AC currents. Moreover, on condition that loop length and AC currents are held constant, spiral type coils have higher transduction efficiency than homocentric squares and figure-of-eight coils.
\end{abstract}

\section{Introduction}

Since the EMAT guided-wave technique can overcome such limitations as low-efficiency and high-cost of some conventional NDT techniques and realize the noncontact, long distance, and quick inspection, it shows some significant advantages for large-scale components inspection. And a typical EMAT, which is used to inspect the plate, mainly includes $\mathrm{AC}$ coils and bias magnets. When the high-frequency current is applied to the AC coil, the coil induces a time-varying magnetic field in the plate. And by coupling the alternating magnetic field in AC coils and the bias magnetic field provided by permanent magnets, an ultrasonic guided-wave is generated in the steel plate via the magnetostrictive effect. Therefore, the excitation parameters of AC coils are the key to influence the performance of EMAT.

Due to the distinguishing characteristics of EMAT over other conventional approaches, simulation and optimization of the EMAT have been extensively studied by many researchers. Dutton et al. improved the efficiency of EMAT by adjusting the coil turns [1]. Jian et al. studied the liftoff effect of EMAT by establishing coil equivalent circuit
[2] and also analyzed the influences of alternating magnetic field generated by AC current on the precision of EMAT $[3,4]$. Yang et al. simulated generation mechanism of the electromagnetic acoustic wave in aluminum plates and analyzed its propagation characteristics [5]. Park et al. investigated the feasibility to inspect internal defects in thin aluminum plate $[6,7]$, and so on. Generally, the EMAT transduction mechanism is different with different materials; for example, the approach only relies on Lorentz force for nonferromagnetic materials, and magnetostrictive force plays leading role in generation of electromagnetic acoustic wave for ferromagnetic materials. Owing to the complexity of the magnetomechanical coupling, it is hard to describe the energy conversation mechanism of material magnetostriction accurately via current finite-element method relying on the analogy between piezoelectricity and piezomagnetism $[8,9]$. With the high-efficiency numerical method being used widely, the FEM based on multiphysics field coupling has become a very useful technique to simulate the magnetostrictive effect. And by using COMSOL multiphysics software, the effects of such excitation parameters as current, frequency, and pulse number in $\mathrm{AC}$ coils on magnetostrictive strain 
TABLE 1: Geometric dimensions and properties parameters of the detected steel plate.

\begin{tabular}{|c|c|c|c|c|c|c|c|c|c|c|c|}
\hline Parameters & Length & Width & Thickness & $\begin{array}{c}\text { Mass } \\
\text { damping } \\
\text { parameter }\end{array}$ & $\begin{array}{c}\text { Stiffness } \\
\text { damping } \\
\text { parameter }\end{array}$ & $\begin{array}{c}\text { Relative } \\
\text { permittivity }\end{array}$ & $\begin{array}{c}\text { Electrical } \\
\text { conductivity }\end{array}$ & $\lambda_{s}$ & $M_{\mathrm{ws}}$ & $\theta$ & $k$ \\
\hline Values & $96[\mathrm{~mm}]$ & $70[\mathrm{~mm}]$ & $6[\mathrm{~mm}]$ & $300[1 / \mathrm{s}]$ & $3.2 e-5[\mathrm{~S}]$ & 1 & $4.032 e 6[\mathrm{~S} / \mathrm{m}]$ & $1.5 e 6[\mathrm{~A} / \mathrm{m}]$ & $1 e 6[\mathrm{~A} / \mathrm{m}]$ & 1 & $4.3 e-4$ \\
\hline
\end{tabular}

TABLE 2: Geometric parameters and magnetic properties parameters of permanent magnets.

\begin{tabular}{|c|c|c|c|c|c|c|c|}
\hline Parameters & $\begin{array}{l}\text { Bias magnet } \\
\text { length }\end{array}$ & $\begin{array}{l}\text { Bias magnet } \\
\text { width }\end{array}$ & $\begin{array}{l}\text { Bias magnet } \\
\text { thickness }\end{array}$ & $\begin{array}{c}\text { Electrical } \\
\text { conductivity }\end{array}$ & $\begin{array}{c}\text { Relative } \\
\text { permeability }\end{array}$ & $\begin{array}{l}\text { Residual flux } \\
\text { density }\end{array}$ & $\begin{array}{c}\text { Relative } \\
\text { permittivity }\end{array}$ \\
\hline Values & $50[\mathrm{~mm}]$ & $20[\mathrm{~mm}]$ & $15[\mathrm{~mm}]$ & $1[\mathrm{~S} / \mathrm{m}]$ & 1.26 & $0.38[\mathrm{~T}]$ & 1 \\
\hline
\end{tabular}

were mainly simulated, and the influence of the coil with different shapes on magnetostrictive strain was also analyzed. Moreover, the simulation results are verified by experiments with the help of a self-developed EMAT guided-wave system.

\section{Constitutive Equations of Ferromagnetic Materials}

As the direction of bias magnetic field is parallel to the surface of the material and perpendicular to the direction of excitation current, the magnetostrictive force is parallel to the material surface. Thus, the magnetostrictive constitutive equations [10] can be written as

$$
\begin{gathered}
\varepsilon_{x}=\frac{1}{E} \sigma+\frac{\lambda_{s}\left(1-\sigma / \sigma_{s}\right)}{M_{w s}^{2}} M_{x}^{2}-\frac{\theta \lambda_{s}\left[M_{x}^{4}-M_{w s}^{4}\left(1-\sigma / \sigma_{s}\right)^{4}\right]}{M_{w s}^{4}}, \\
H_{x}=\frac{1}{k} f^{-1}\left(\frac{M_{x}}{M_{s}}\right)-\frac{\lambda_{s}\left(2-\sigma / \sigma_{s}\right)}{\mu_{0} M_{s}^{2}} M_{x} \\
+\frac{4 \theta \lambda_{s} \sigma\left[M_{x}^{3}-\sigma_{s} M_{w s}^{3}\left(1-\sigma / \sigma_{s}\right)^{3}\right]}{\mu_{0} M_{w s}^{4}}
\end{gathered}
$$

where (1) describes the magnetostrictive effect and (2) describes the inverse magnetostrictive effect. And the first item in (1) represents the inherent elasticity of materials and shows the linear relationship between materials strain and the applied stress, the second reflects the effects of the magnetic domain rotation on the elasticity due to stress anisotropy, and the last shows the influence of magnetomechanical coupling on the elasticity. And $\varepsilon_{x}$ is response variables, $\lambda_{s}$ is saturation magnetostriction, $M_{w s}$ is magnetic domain wall magnetization, $M_{x}$ is magnetization intensity, $\mu_{0}$ is the magnetic permeability of free space and is equal to $4 \pi \times$ $10^{-7} \mathrm{Hm}^{-1}, M_{s}$ is saturation magnetization, $k$ and $\theta$ represent relaxation factor, $k$ is related to saturation magnetic field, $\theta$ describes relations of $M_{x}$ and the initial magnetization, $f(x)=\operatorname{coth}(x)-x^{-1}, \sigma$ represents the applied stress, and $\sigma_{s}$ represents the saturation stress.
If the applied stress of the material is zero, the magnetostrictive constitutive relations can be simplified as follows:

$$
\begin{aligned}
\varepsilon_{x} & =\frac{M_{x}^{2} \lambda_{s}}{M_{w s}^{2}}-\frac{\theta \lambda_{s}\left(M_{x}^{4}-M_{w s}^{4}\right)}{M_{w s}^{4}}, \\
H_{x} & =\frac{1}{k} f^{-1}\left(\frac{M_{x}}{M_{s}}\right)-\frac{2 \lambda_{s}}{\mu_{0} M_{w s}^{2}} M_{x} .
\end{aligned}
$$

\section{Effects of Excitation Parameters on Magnetostrictive Strain}

3.1. Finite Element Model of EMAT for Steel Plates Inspection. A finite element model of EMAT which is used to inspect steel plates, shown as Figure 1, is established by COMSOL multiple-physics software, which mainly consists of two permanent magnets and a homocentric-squares coil. The geometric dimensions and the properties parameters of the detected steel plate are shown as Table 1 , and its $B$ $H$ curve is shown as Figure 2. Material Nd-Fe-B N50 is chosen for the bias magnetic pole, and its magnetic properties parameters are shown as Table 2 . In the mesh generation, such rectangular regions as permanent magnets and steel plates are divided by mapped-swept method firstly; then the rectangular grid is transformed into free tetrahedral elements using insert diagonal edges method, where the maximum element size is $5.28 \mathrm{~mm}$, and the minimum element size is $0.384 \mathrm{~mm}$. And other regions are meshed by adaptive free tetrahedral method, where the maximum element size is $14.4 \mathrm{~mm}$, the minimum element size is $2.69 \mathrm{~mm}$, the maximum element growth rate is 1.6 , the curvature factor is 0.7 , and the resolution of narrow regions is 0.4 . The expression of excitation current in the homocentric-squares coil is shown as

$$
i=0.5 \times I \times \frac{1-\cos (2 \times \pi \times f \times t)}{6} \times \cos (a \times \pi \times f \times t),
$$

where $I$ represents current, $f$ is excitation frequency, and $a$ represents coefficient of pulse number.

3.2. Effects of AC Current Density on Magnetostrictive Vibration. According to (4), the initial values of loaded current in AC coils are specified as $I=10 \mathrm{~A}, f=120 \mathrm{kHz}$, and 


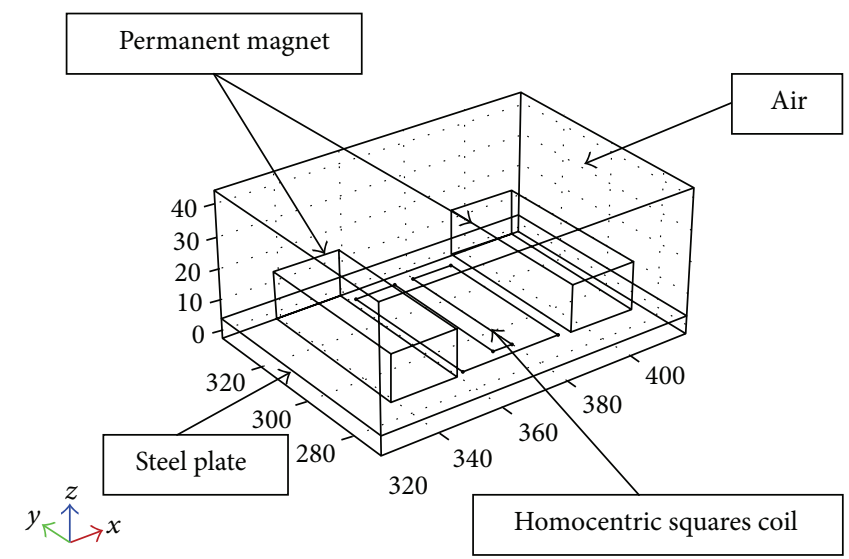

FIgURE 1: FEM of EMAT for plates inspection.

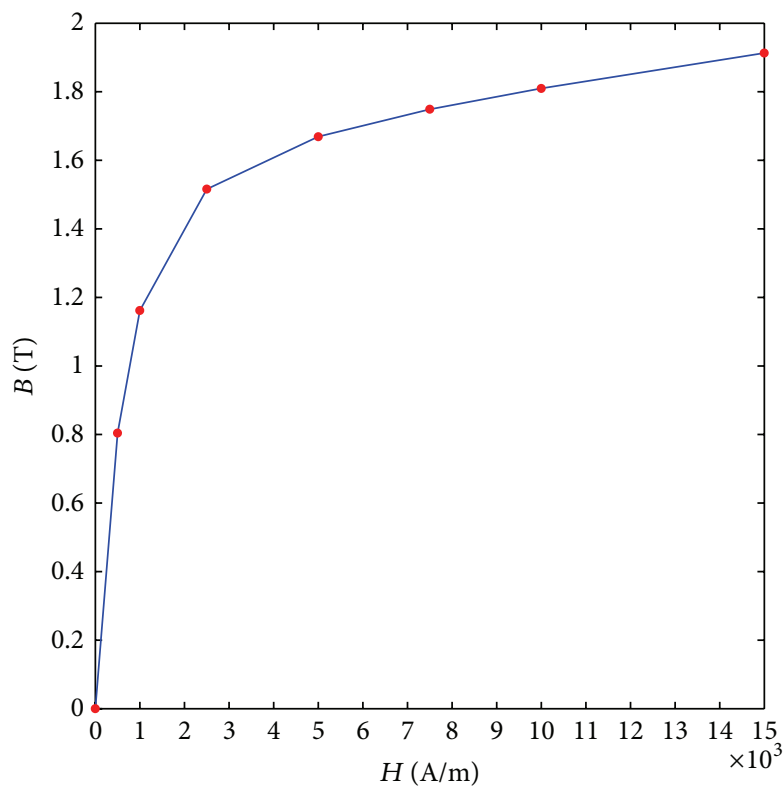

FIgURE 2: $B-H$ curve of steel plates.

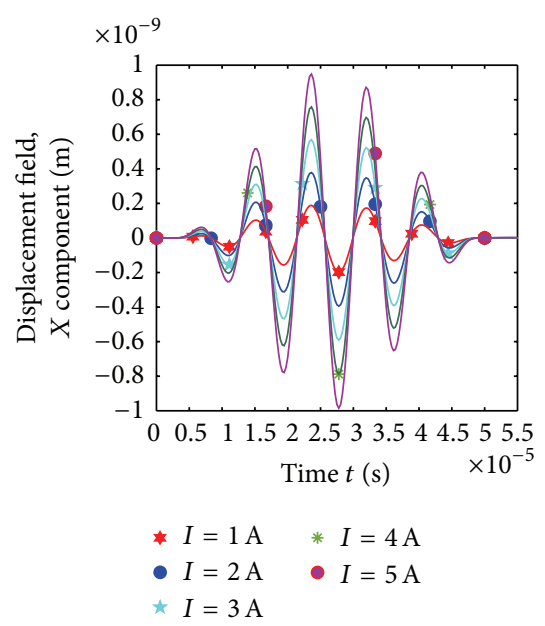

(a) AC current-magnetostrictive strain

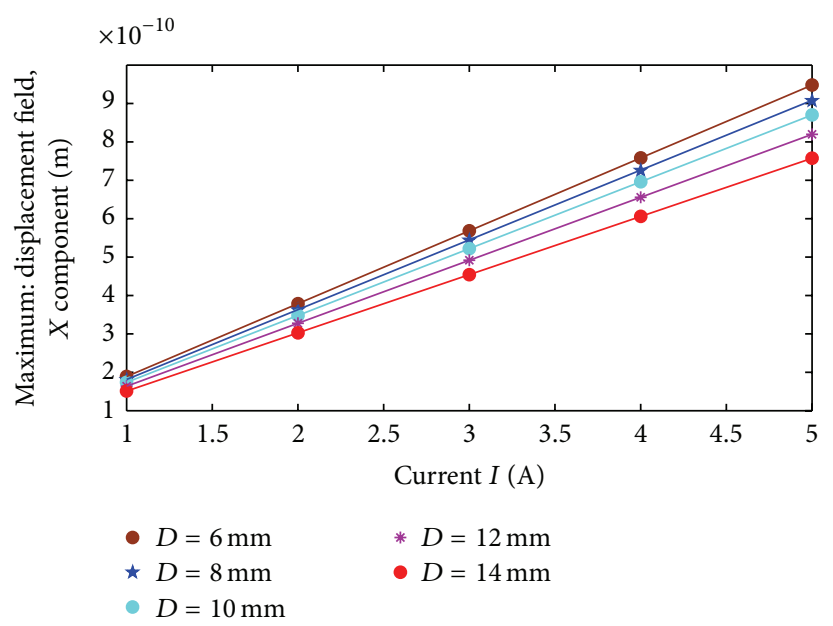

(b) AC current-magnetostriction with different plate thickness

FIGURE 3: Effects of excitation current on magnetostrictive strain. 


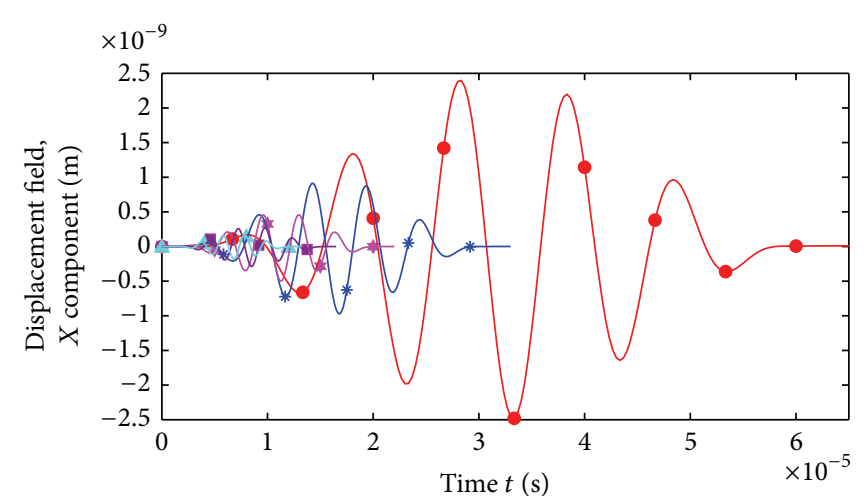

- $f=100 \mathrm{kHz}$

* $f=200 \mathrm{kHz}$

* $f=300 \mathrm{kHz}$

(a) Current frequency-magnetostrictive strain

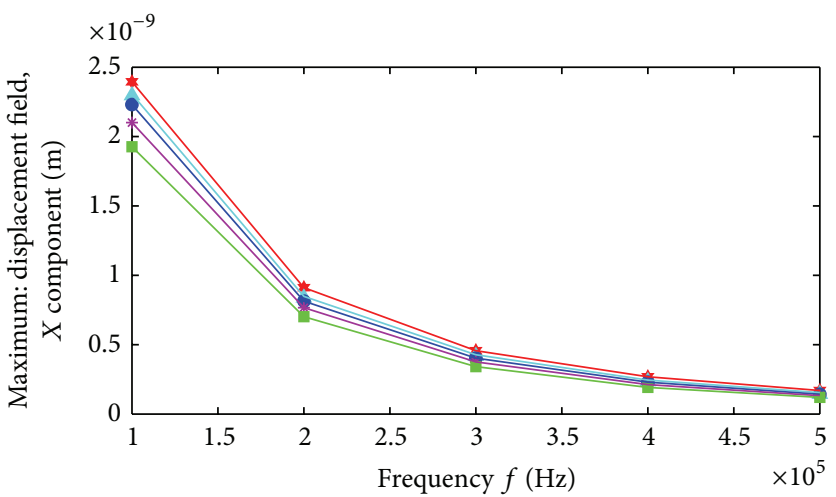

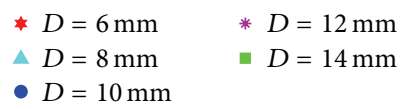

(b) Frequency-magnetostriction with different plate thickness

FIGURE 4: Effects of excitation frequency on magnetostrictive strain.

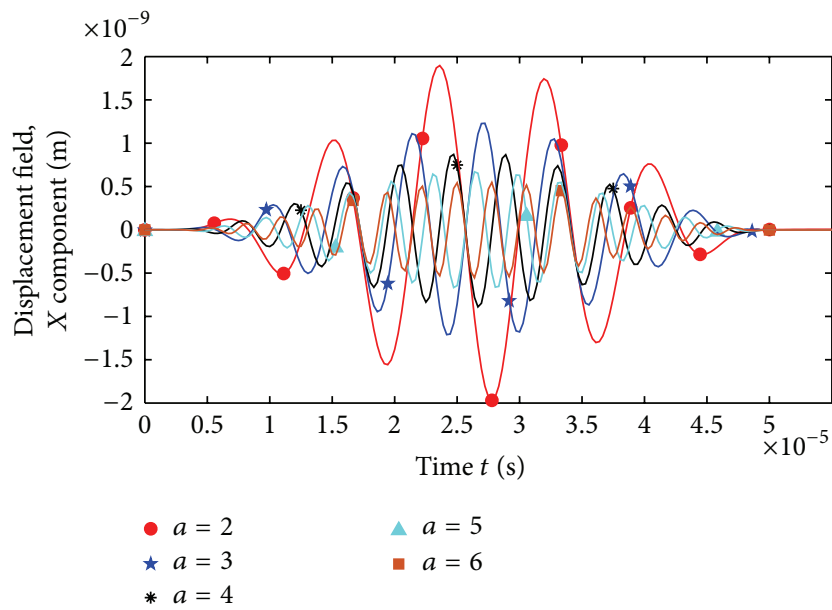

(a) Pulse number-magnetostrictive strain

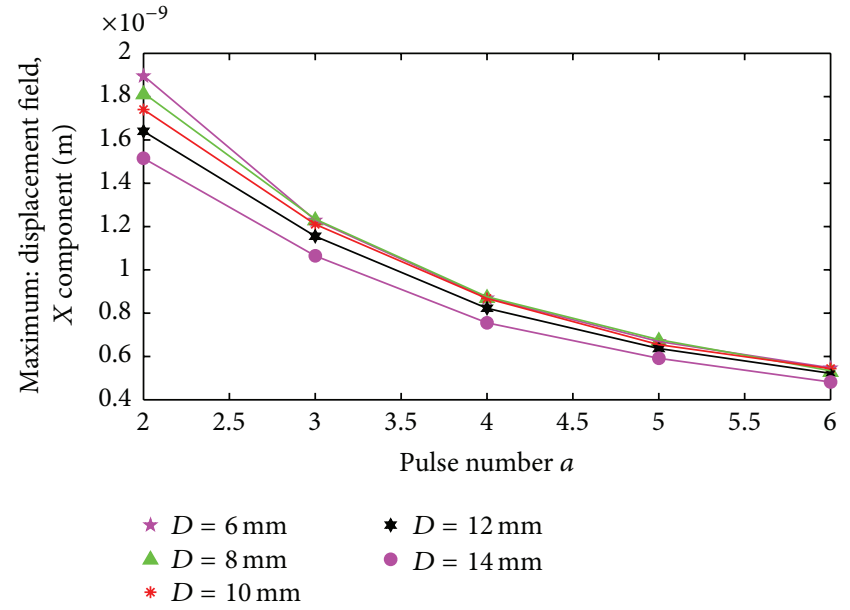

(b) Pulse number-magnetostriction with different plate thickness

FIGURE 5: Effects of pulse number on magnetostrictive strain.

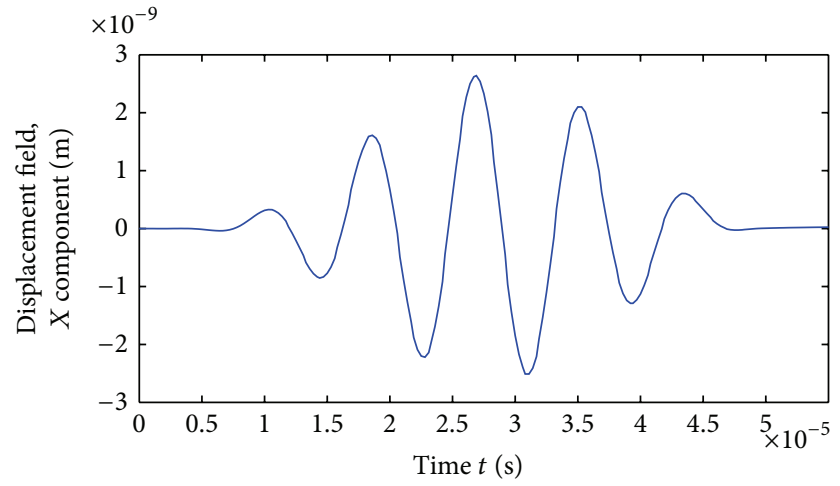

(a) Magnetostriction of spiral type coils

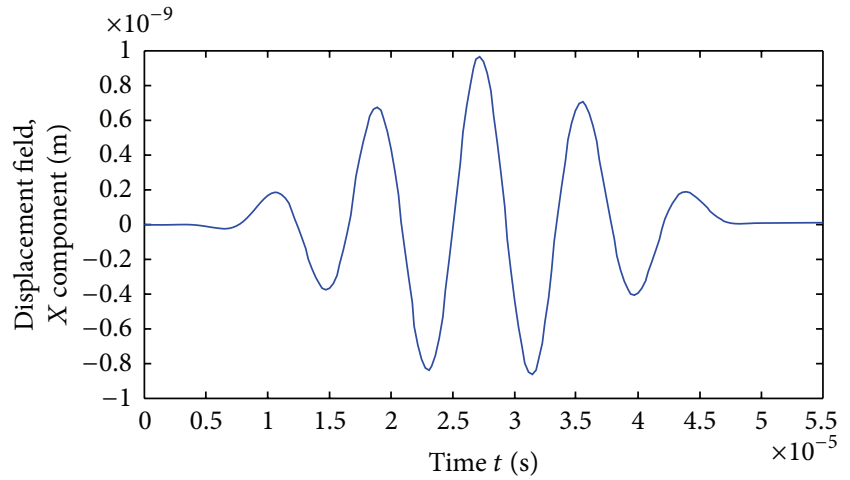

(b) Magnetostriction of figure-of-eight coils

FIGURE 6: Magnetostrictive displacement with different coil types. 


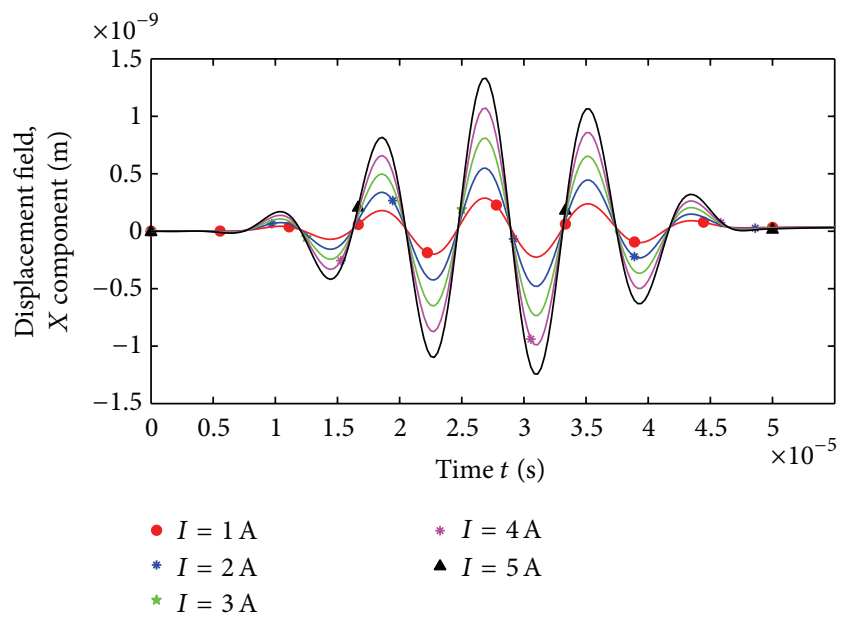

(a) Magnetostriction-current density

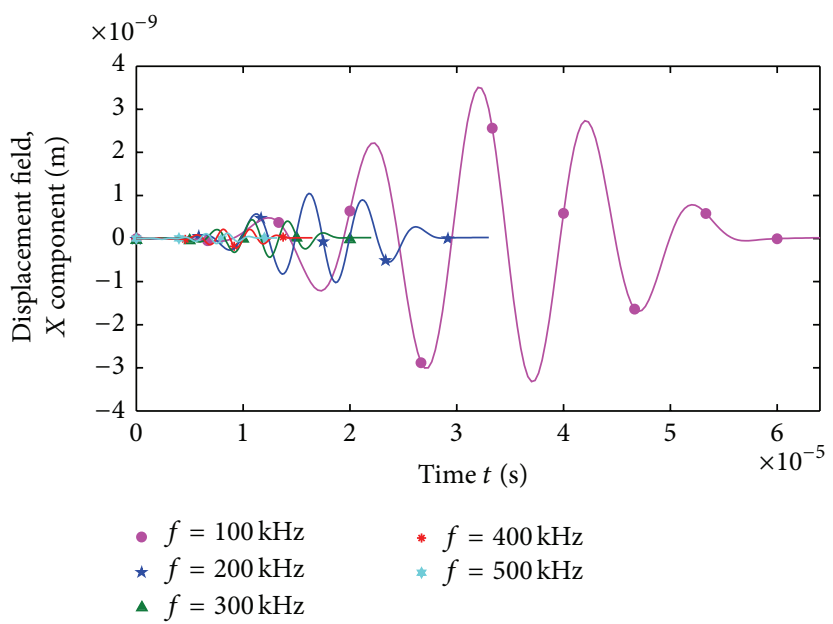

(b) Magnetostriction-excitation frequency

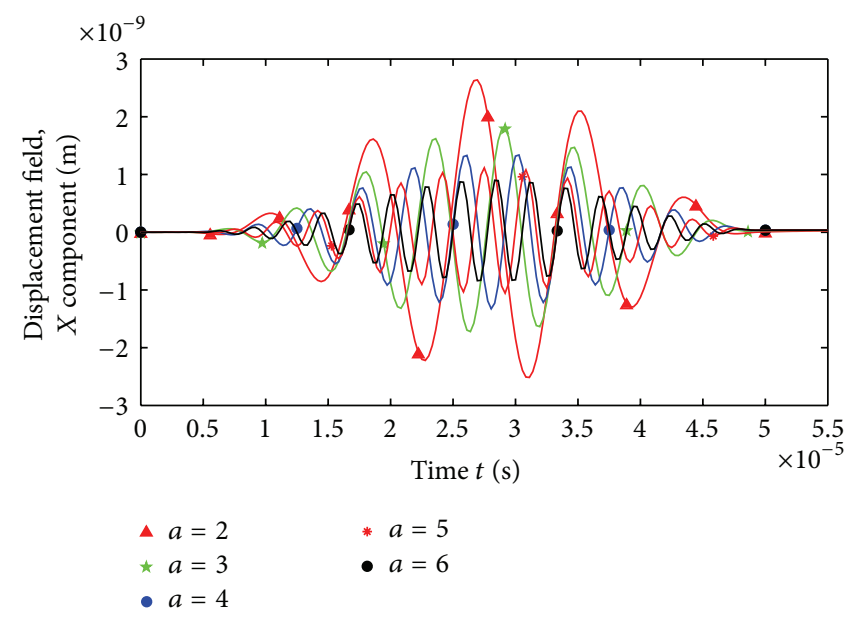

(c) Magnetostriction-pulse number

FIGURE 7: Magnetostriction of spiral type coils.

$a=2$, respectively. Using of the COMSOL finite element analysis software, the magnetostritive displacements in steel plates are calculated with different excitation parameters in order to analyze the influences of excitation parameters on the magnetostrictive strain. The results can be used to set excitation parameters in accordance with geometric dimensions of the detected steel plate and obtain the best transduction efficiency in practical inspection.

Figure 3(a) shows the influences of the excitation current on magnetostritive displacements, where the current density is from 1 to $5 \mathrm{~A}$, respectively. It can be seen that magnetostrictive vibration increases continuously with the increasing of AC current intensity. Figure 3(b) shows the relation between the magnetostritive displacements and the current intensity for different steel plate thickness $(D)$, and it is nearly linear if the excitation frequency and pulse number are held constant. Moreover, it is found that the magnetostritive displacement decreases gradually with a continuously increasing plate thickness.
3.3. Effects of Excitation Frequency on Magnetostrictive Vibration. Figure 4 shows the influences of the excitation frequency on magnetostritive displacements if the other parameters are held constant, where the AC current frequency is from 100 to $500 \mathrm{kHz}$, respectively. It is found that both the magnetostrictive vibration amplitude and the magnetostrictive period decrease with the increase of the current frequency loaded in AC coils. A possible cause of this phenomenon is that the vibration period could shorten simultaneously and cause the times of particle vibration passing balance point per unit time to increase as the excitation frequency increases. Moreover, since the material damping increases with the decrease of particle vibration period, the magnetostrictive amplitude decreases. From Figure 4(b), it can be seen that the magnetostrictive amplitude decreases with the excitation frequency. And it decreases sharply at first, but when the excitation frequency exceeds a certain value and the plate undergoes gradual magnetostrictive saturation, and the increment of magnetostrictive displacement becomes 


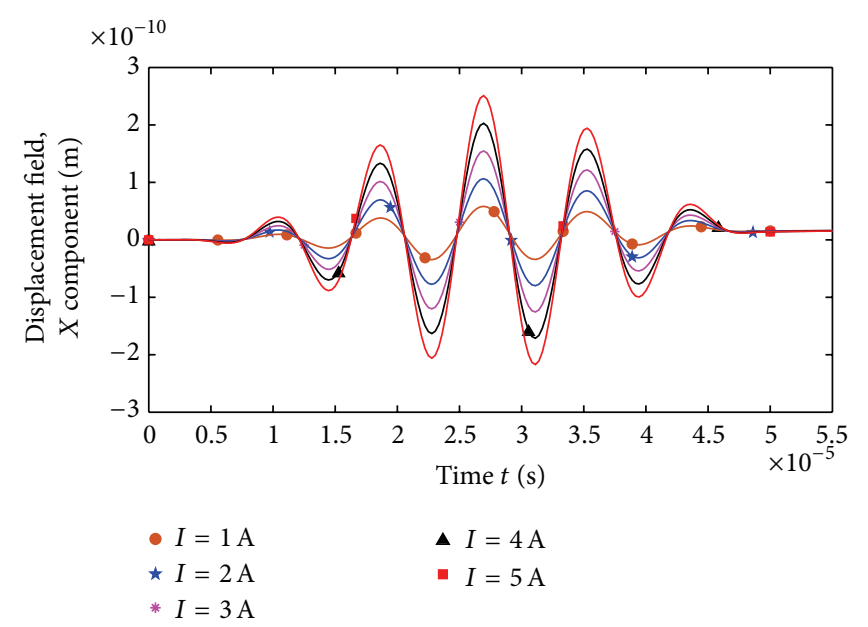

(a) Magnetostriction-current density

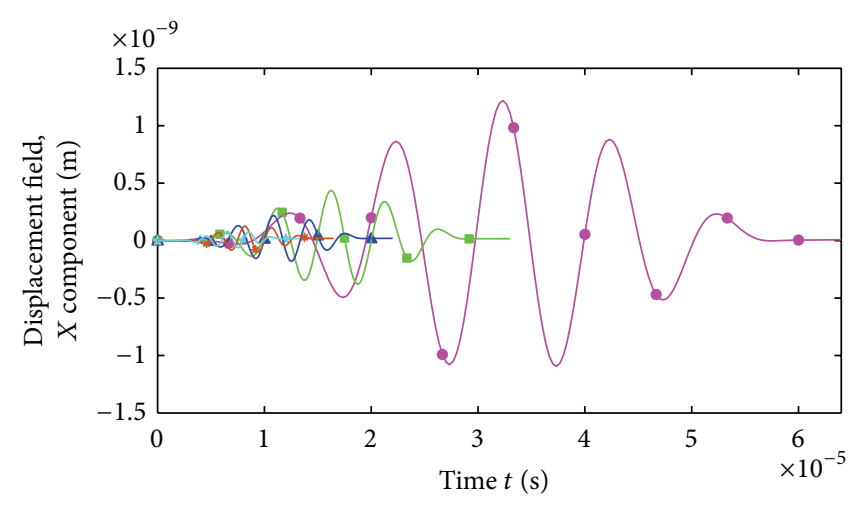

$\begin{array}{rl}\text { - } f=100 \mathrm{kHz} & * f=400 \mathrm{kHz} \\ \text { - } f=200 \mathrm{kHz} & * f=500 \mathrm{kHz} \\ \text { - } f=300 \mathrm{kHz} & \end{array}$

(b) Magnetostriction-excitation frequency

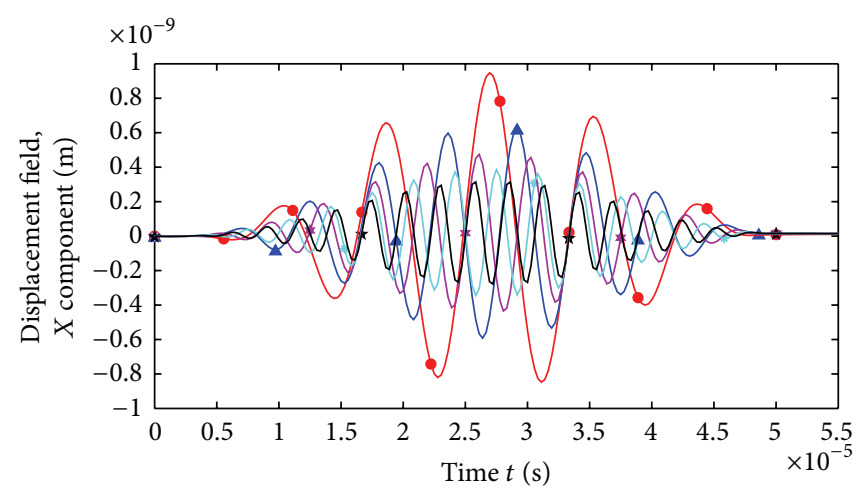

$$
\begin{array}{ll}
\text { - } a=2 & * a=5 \\
\text { × } a=3 & \star a=6 \\
\text { * } a=4 &
\end{array}
$$

(c) Magnetostriction-pulse number

FIGURE 8: Magnetostriction of figure-of-eight coils.

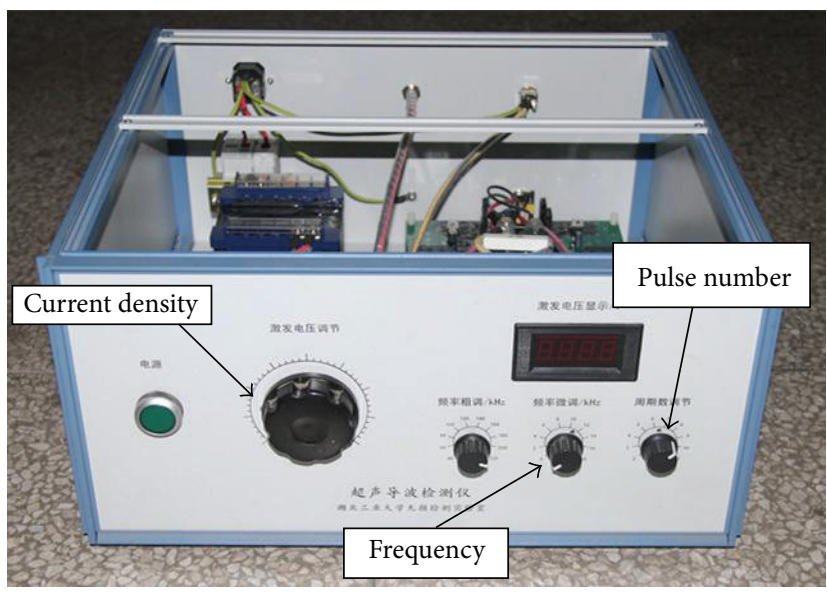

FIGURE 9: Exciting signal source. 


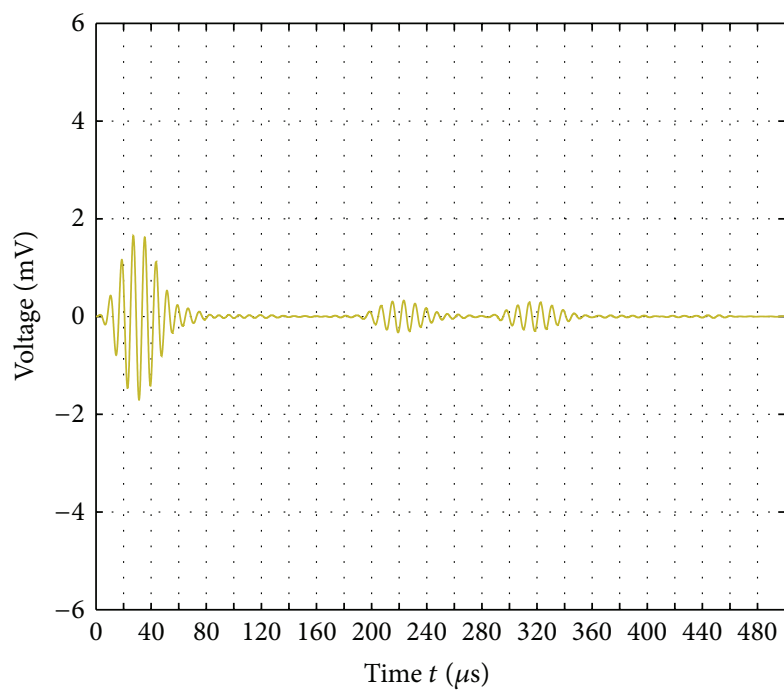

(a) $I=3 \mathrm{~A}$

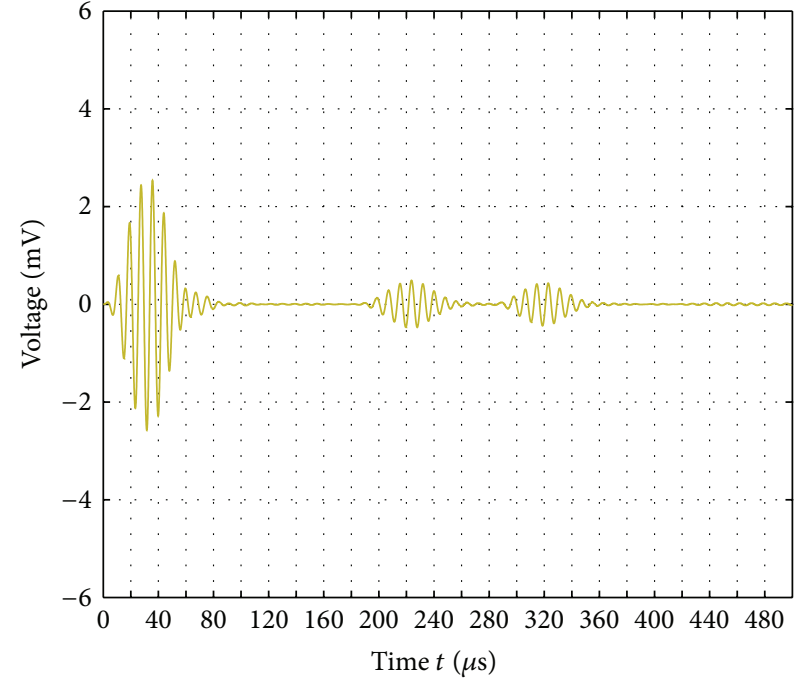

(b) $I=4 \mathrm{~A}$

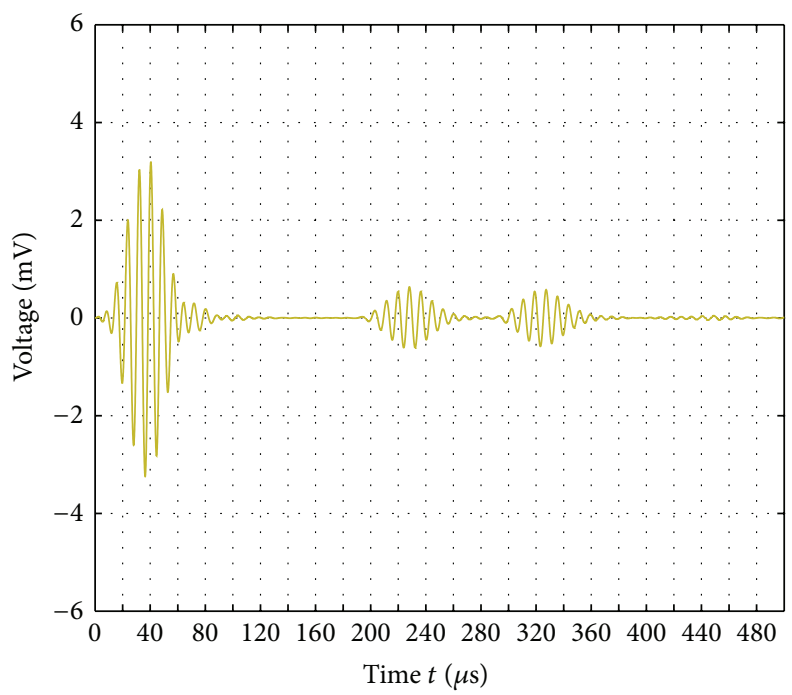

(c) $I=5 \mathrm{~A}$

FIGURE 10: Testing signals with different current density.

slow. Additionally, on condition that excitation parameters are held constant, the magnetostritive displacement decreases with the plate thickness.

\subsection{Effects of AC Current Pulse Number on Magnetostrictive} Vibration. Figure 5(a) shows the relations of the AC current pulse number on magnetostritive displacements, where the pulse number is from 2 to 6 , respectively. It is found that the increase of pulse number could decrease the transduction efficiency and cause the amplitude of magnetostrictive vibration to decrease. A possible reason of this phenomenon is that the times of particle vibration passing balance point per unit time could increase simultaneously and cause the velocity of magnetostrictive vibration to increase as the pulse number increases. And because the material damping increases with the decrease of particle vibration velocity, the magnetostrictive amplitude decreases. From Figure 5(b), it can be seen that the magnetostrictive amplitude decreases sharply at first with the pulse number, and when the pulse number exceeds 4 and the plate undergoes gradual magnetostrictive saturation, the increment of magnetostrictive displacement becomes slow. Similarly, on condition that excitation parameters are held constant, the magnetostritive displacement also decreases with the plate thickness.

\section{Effects of AC Coil Shapes on Transduction Efficiency of EMAT}

In order to study the influence of AC coil types on transduction efficiency of EMAT, a $235 \mathrm{~mm}$ long enameled wire is wound in such three shapes as spiral type coils, figureof-eight, and homocentric squares. According to the above analysis, an AC current with the same excitation parameters is 


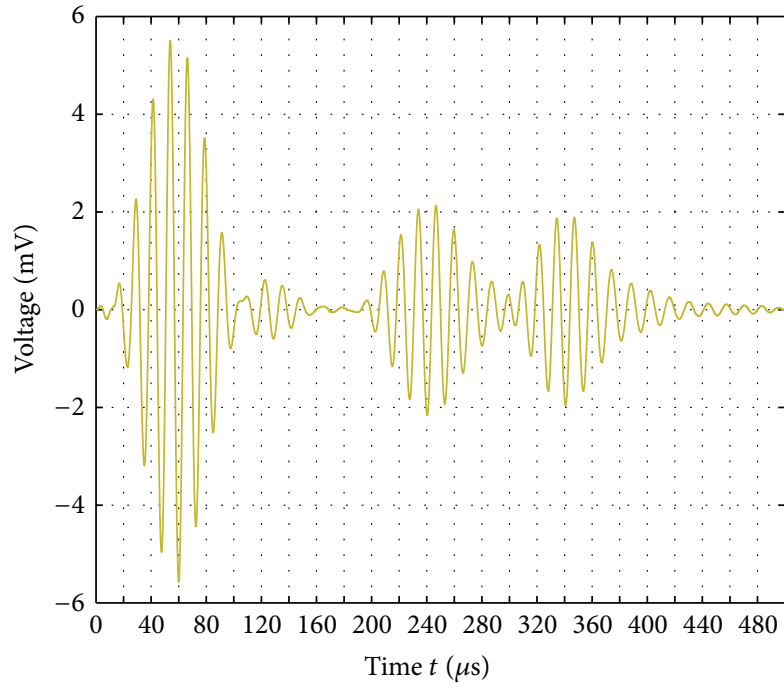

(a) $f=100 \mathrm{kHz}$

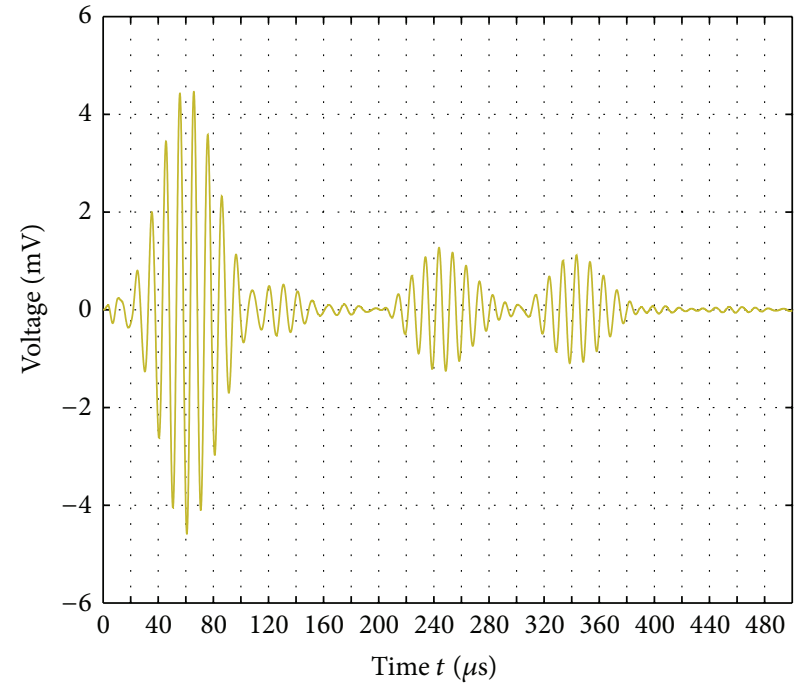

(b) $f=200 \mathrm{kHz}$

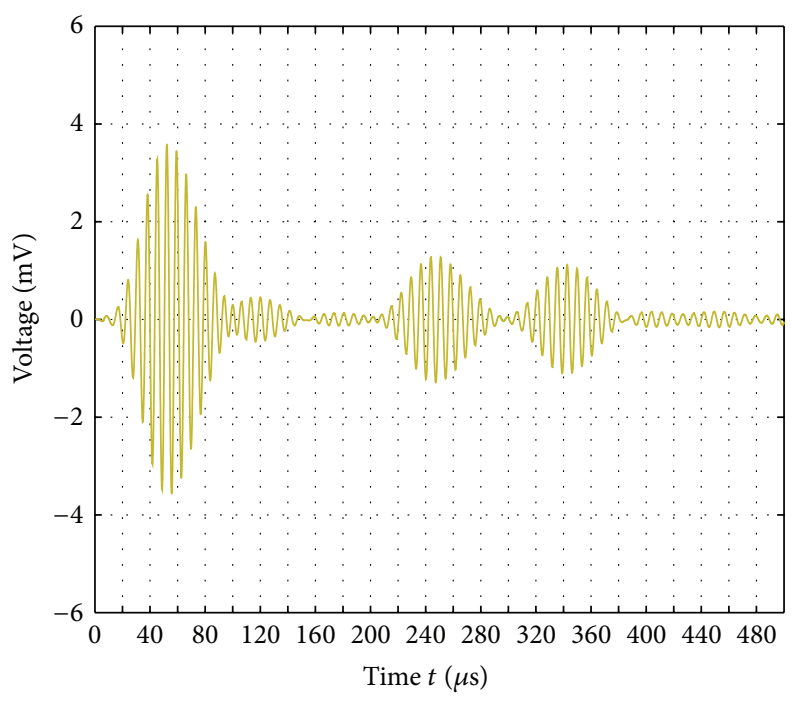

(c) $f=300 \mathrm{kHz}$

FIGURE 11: Testing signals with different excitation frequency.

loaded in the AC coils, and some calculated results are shown in Figure 6. It is found that the maximum magnetostrictive displacement of spiral type coils, figure-of-eight, and homocentric squares are $2.63703 \times 10^{-9} \mathrm{~mm}, 9.47149 \times 10^{-10} \mathrm{~mm}$, and $1.89573 \times 10^{-9} \mathrm{~mm}$, respectively. Obviously, on condition that loop length and excitation current are constant, the spiral type coil has higher transduction efficiency than figure-ofeight coils and homocentric squares.

Figures 7 and 8 show the influence of excitation parameters on transduction efficiency of EMAT with spiral type coils and figure-of-eight coils, respectively, where the loaded AC current density is from 1 to $5 \mathrm{~A}$, the excitation frequency is from 100 to $500 \mathrm{kHz}$ and the pulse number is from 2 to 6 . It is found that the generated magnetostriction of AC coils with different shapes show the same influence with variation of excitation parameters. That is to say, the transduction efficiency of different AC coils increases with an increasing of AC current density, but it decreases with an increasing of the excitation frequency and pulse numbers.

\section{Experimental Analysis}

According to the above analysis, in the experimental condition, a steel plate with $6 \mathrm{~mm}$ thickness, $80 \mathrm{~mm}$ width, and $400 \mathrm{~mm}$ length is selected as the inspected sample, and a through hole with $3 \mathrm{~mm}$ diameter is drilled on the surface of the plate. An EMAT, whose AC coils are spiral shapes and bias pole pieces are two $20 \mathrm{~mm}$ wide and $15-\mathrm{mm}$-height permanent magnets, is applied to inspect the plate and to verify the simulation results. Adjusting the button of current, frequency, and pulse number of the exciting signal source as shown in Figure 9, some testing signals can be obtained 


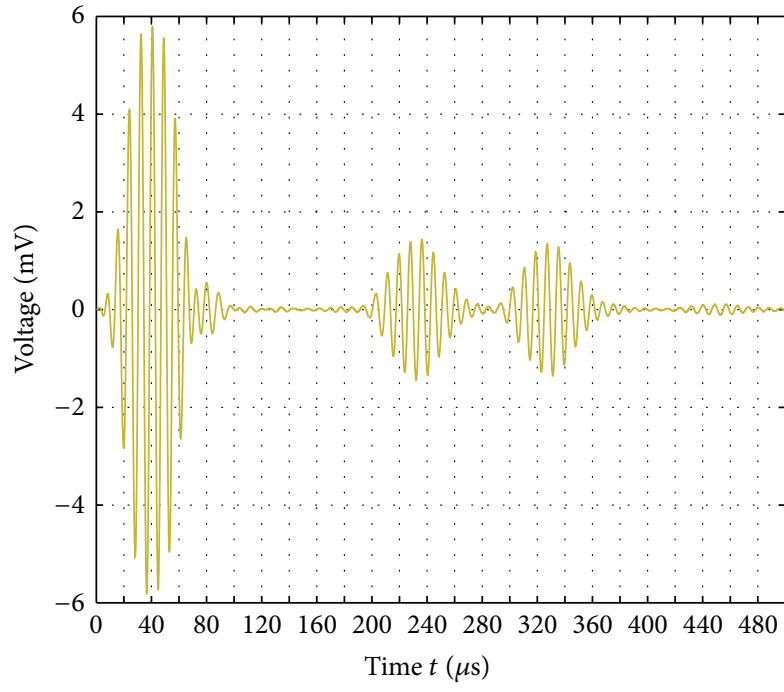

(a) $a=2$

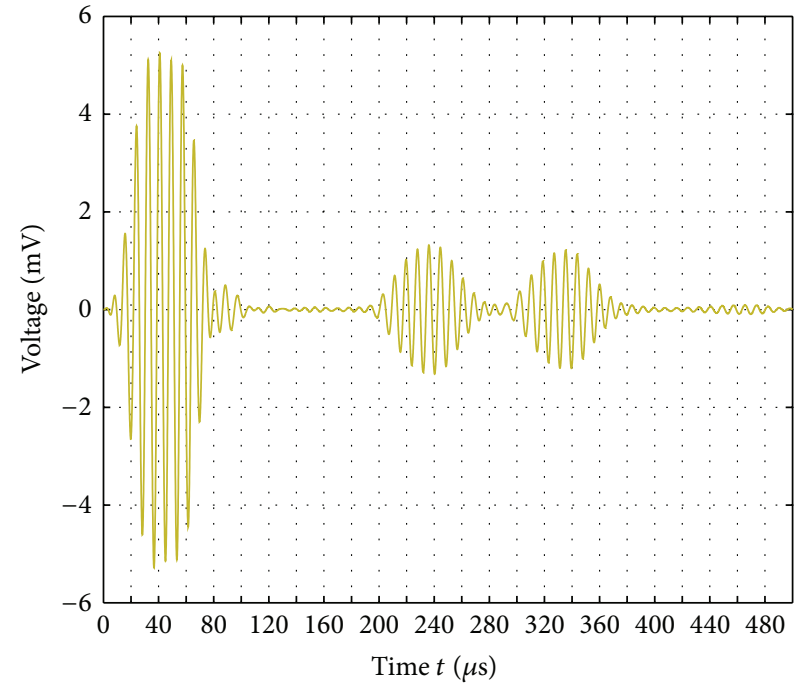

(b) $a=3$

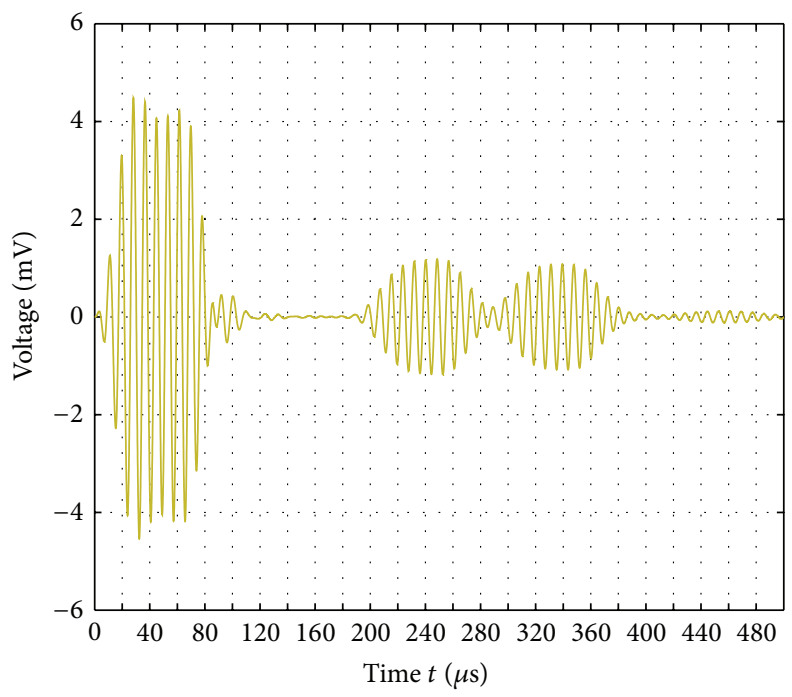

(c) $a=4$

FIGURE 12: Testing signals with different pulse numbers.

and shown in Figures 10, 11, and 12, respectively. Exacting the maximum amplitude of defect signals, the effects of AC excitation parameters on the echo signals are shown as Figure 13. It can be seen that the magnetostrictive vibration increases continuously with the applied current density, but the magnetostrictive vibration decreases with the applied excitation frequency and pulse number. Compared with the FEM calculated results shown in Figures 3(b), 4(b), and 5 (b), it is found that the experimental results are basically consistent with simulation data, which indicates that the finite element model is correct and simulation results are reliable.

\section{Conclusions}

Based on the constitutive equation of magnetostrictive material, a finite element model of EMAT for steel plates inspection is established by COMSOL multiple-physics software, the effects of AC excitation parameters on magnetostrictive displacements have been mainly simulated, and the influence of AC coil shapes on EMAT transduction efficiency are also analyzed. Moreover, successful comparisons have been obtained by a validation experimental case for a steel plate with a through hole in the center. Works in progress are focusing on optimizing transmitters or receivers of EMAT guided-wave, which can provide theoretical and methodological basis for choosing the excitation parameters in practical EMAT applications.

\section{Conflict of Interests}

The authors declare that there is no conflict of interests regarding the publication of this paper. 


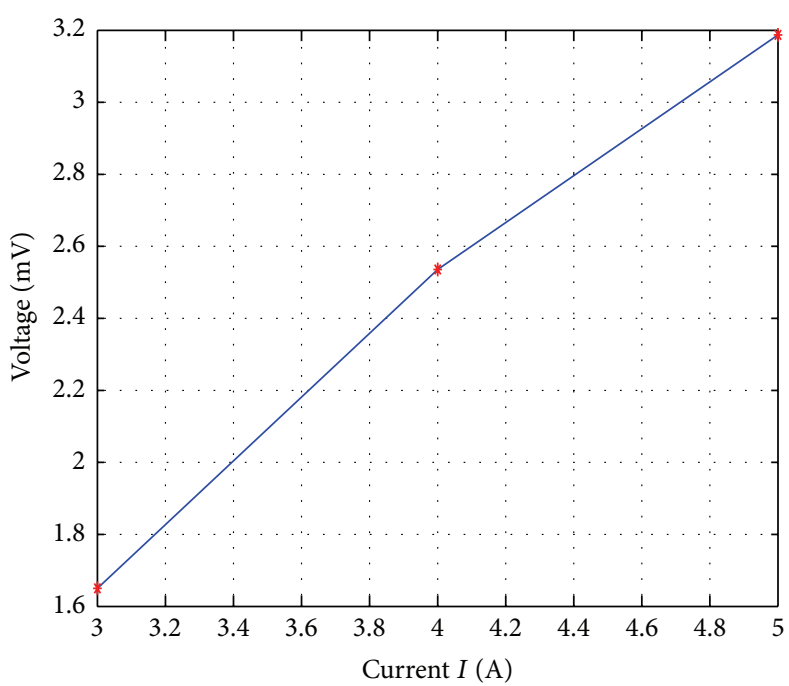

(a) AC current-testing signals voltage

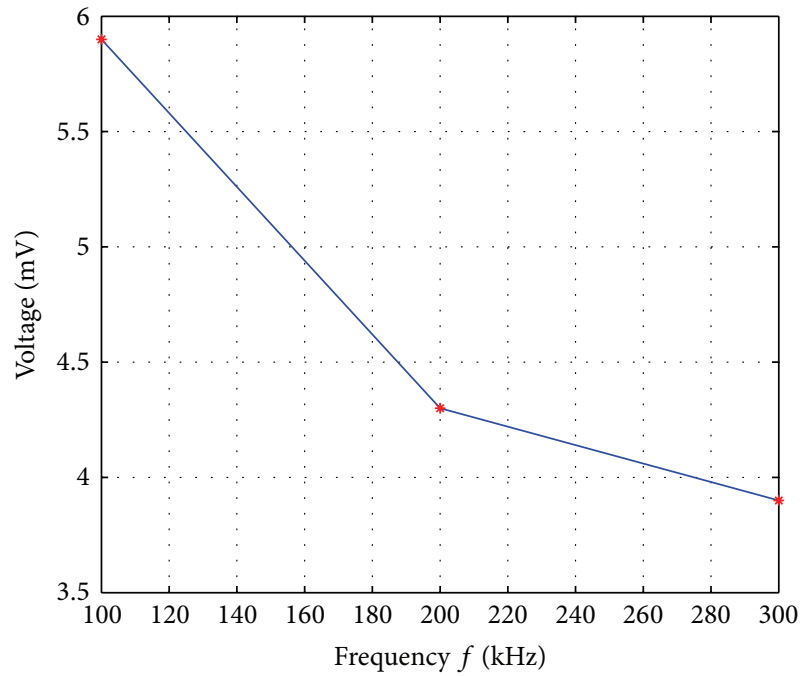

(b) Current frequency-testing signals voltage

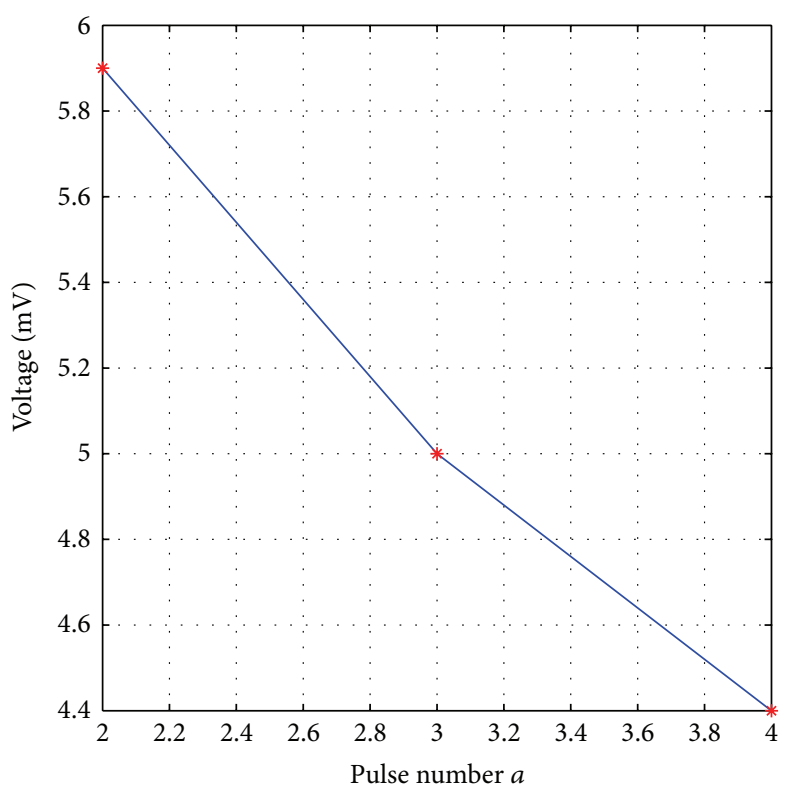

(c) Pulse number-testing signals voltage

FIGURE 13: Testing signals voltage with different AC coils parameters.

\section{Acknowledgments}

This work is supported by the National Key Scientific Apparatus Development of Special Item (2013YQ140505), the Natural Science Foundation of Hubei Province (2014CKB506), and Program for Excellent Young and Middle-aged Innovation Team of Hubei Province (no. T201105).

\section{References}

[1] B. Dutton, S. Boonsang, and R. J. Dewhurst, "A new magnetic configuration for a small in-plane electromagnetic acoustic transducer applied to laser-ultrasound measurements: modelling and validation," Sensors and Actuators A: Physical, vol. 125, no. 2, pp. 249-259, 2006.
[2] X. Jian, S. Dixon, and S. B. Palmer, "In-plane and out-of-plane particle velocity measurement using electromagnetic acoustical transducers," in Proceedings of the IEEE Ultrasonics Symposium, pp. 1276-1279, September 2005.

[3] X. Jian, S. Dixon, R. S. Edwards, and J. Reed, "Coupling mechanism of electromagnetic acoustical transducers for ultrasonic generation," The Journal of the Acoustical Society of America, vol. 119, no. 5, pp. 2693-2701, 2006.

[4] X. Jian, S. Dixon, R. S. Edwards, and J. Morrison, "Coupling mechanism of an EMAT," Ultrasonics, vol. 44, pp. e653-e656, 2006.

[5] L.-J. Yang, C.-H. Li, W.-P. Gao, and S. Gao, "Finite element simulation of the generation and propagation processes of electromagnetic ultrasonic wave in aluminum plate test," Chinese Journal of Scientific Instrument, vol. 33, no. 6, pp. 1218-1223, 2012. 
[6] I.-K. Park, T.-H. Kim, H.-M. Kim, Y.-K. Kim, Y.-S. Cho, and W.-J. Song, "Evaluation of hidden corrosion in a thin plate using a non-contact guided wave technique," Key Engineering Materials, vol. 321-323, pp. 492-496, 2006.

[7] Z.-C. Li, Modeling and Research of EMAT Based on Lorentz Mechanism, Harbin Institute of Technology, Harbin, China, 2010.

[8] Z.-H. Liu, N. Wang, C.-F. He, B. Yu, and B. Wu, "Experimental research on experimental research on excitation of single mode of lamb waves and defect detection by using piezoelectric ceramic wafers," Journal of Beijing University of Technology, vol. 37, no. 10, pp. 1453-1458, 2011.

[9] G. Zhai, K. Wang, Y. Wang, R. Su, and L. Kang, "Analytical modeling and analysis of electromagnetic acoustic transducers with spiral coils," Proceedings of the Chinese Society of Electrical Engineering, vol. 33, no. 18, pp. 147-154, 2013.

[10] H.-M. Zhou, Y.-H. Zhou, X.-J. Zheng, Q. Ye, and J. Wei, "A general 3-D nonlinear magnetostrictive constitutive model for soft ferromagnetic materials," Journal of Magnetism and Magnetic Materials, vol. 321, no. 4, pp. 281-290, 2009. 


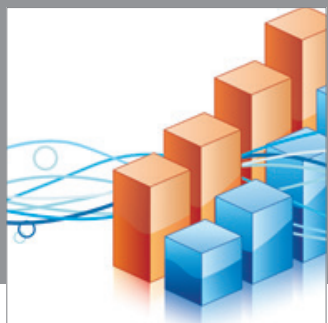

Advances in

Operations Research

mansans

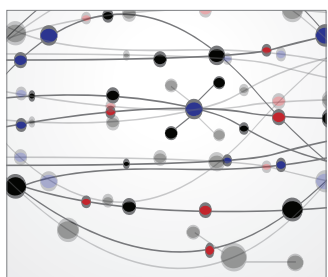

The Scientific World Journal
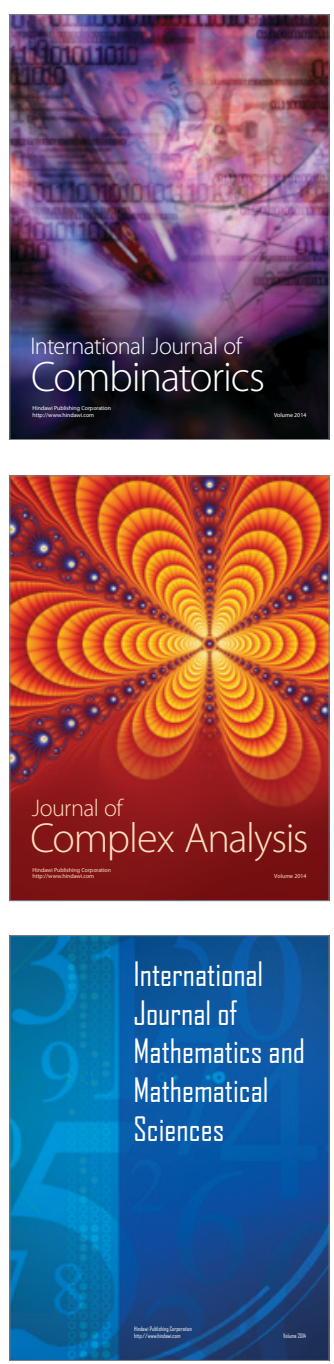
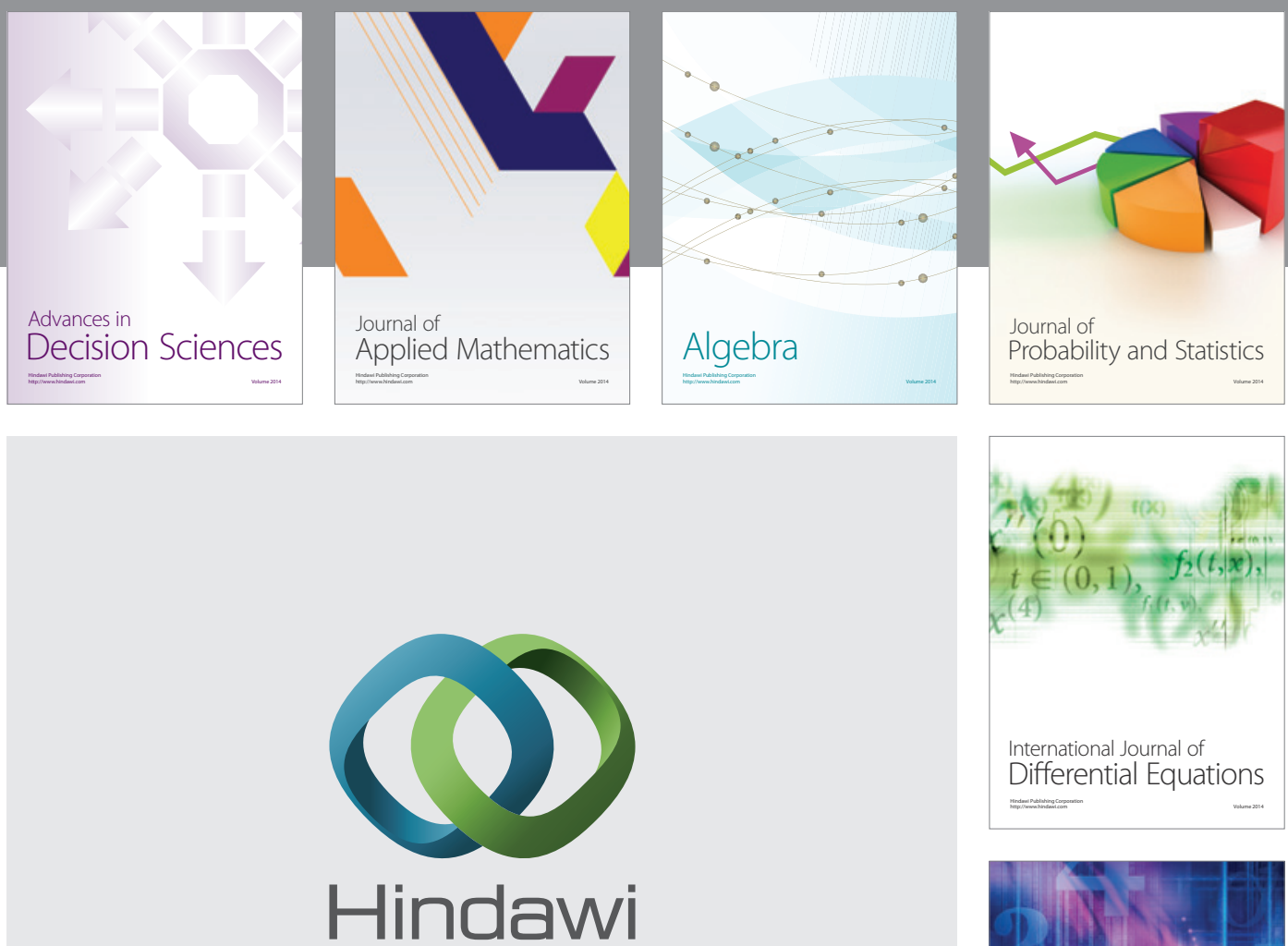

Submit your manuscripts at http://www.hindawi.com
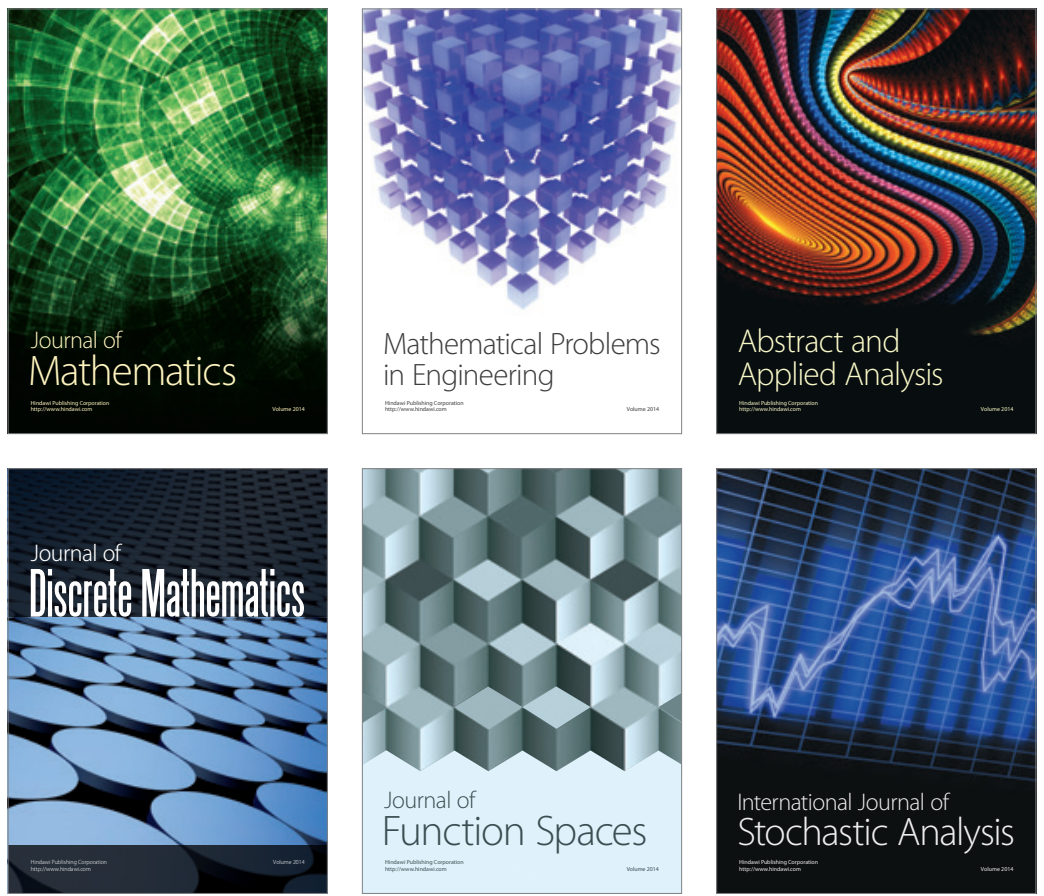

Journal of

Function Spaces

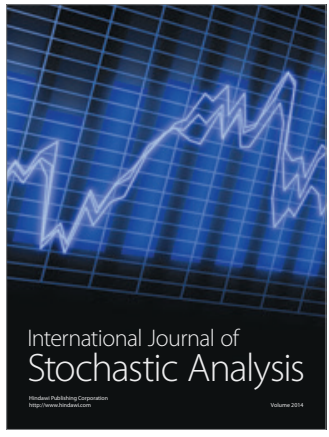

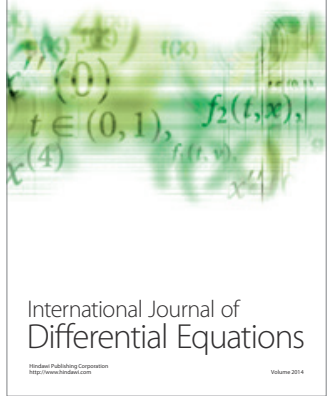
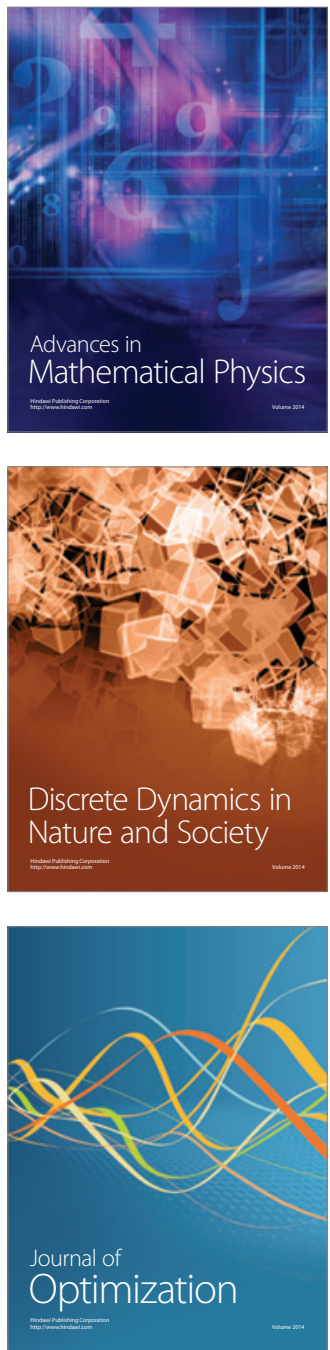